\title{
Surabaya Zoo: a social enterprise on the cross road
}

\section{Aluisius Hery Pratono, Mario Antonio Lopez and Ruswiati Surya Saputra}

Aluisius Hery Pratono is a Lecturer at the University of Surabaya, Surabaya, Indonesia.

Mario Antonio Lopez is a Professor at the Asian Institute of Management, Makati, Philippines.

Ruswiati Surya Saputra is an Educator at the

University Utara Malaysia, Sintok, Malaysia.
Mr Samson, a senior official at Surabaya City Government, pondered over the proposal in his hands. Along with his authority for overseeing the budget of the local government, he was fully aware that he had to make an emergency decision about the proposed budget of USD150 million (Antara, 2013).

He could not continue to ignore the situation of the animals, given his deeply rooted ethical convictions. Due to an unresolved management conflict, the zoo apparently failed to reach expectations. A number of animals, as well as workers, suffered because of a longstanding management conflict. This called for a quick response from the local authority with which Mr Samson was involved. He would have to decide whether the zoo would close or continue operating.

Typically the promotion of animal rights is not prioritized by law enforcers in emerging economies (Dallas, 2013). The effort to provide more resources for animal welfare is not a priority for local public policymakers when so many people still live on the poverty line. However, this zoo disaster had attracted international attention. For example, Tierpark Berlin, Germany, and CNN came to Surabaya Zoo on March 24, 2012 (Suara Surabaya, 2012). They highlighted the problems of too many animals in their cages and the poor quality of the animals' food. 